\title{
molecules
}

ISSN 1420-3049

http://www.mdpi.org

\section{Synthesis of Some Phenylpropanoid Monoglycerides via the Mitsunobu Protocol}

\author{
Daniela I. Batovska ${ }^{1,2}$, Takao Kishimoto ${ }^{1}$, Vassya S. Bankova ${ }^{2}$, Zornitsa G. Kamenarska ${ }^{2}$ and \\ Makoto Ubukata ${ }^{1, *}$ \\ ${ }^{1}$ Hokkaido University, Graduate School of Agriculture, Kita-9, Nishi-9, Kita-ku, Sapporo 0608589, \\ Japan; Tel./Fax: (+81)-11-706-3638 \\ ${ }^{2}$ Institute of Organic Chemistry with Centre of Phytochemistry, Bulgarian Academy of Sciences, "Acad. \\ G. Bonchev" Str., bl.9, Sofia 1113, Bulgaria; Tel.: (+359) 2-9606-134, Fax: (+359) 2-87-700-225 \\ * To whom correspondence should be addressed. E-mail: m-ub@for.agr.hokudai.ac.jp
}

Received: 17 August 2004; in revised form: 24 January 2005 / Accepted: 28 January 2005 / Published: 31 March 2005

\begin{abstract}
Natural monoglycerides of cinnamic, ferulic and $p$-coumaric acids were synthesized in good to high overall yields from isopropylidene glycerol via the Mitsunobu reaction and further deprotection of the corresponding acetonides with Amberlyst 15. The method avoids the need of protection of the phenolic hydroxyls. During the Mitsunobu esterifications a strong influence of the acid strength on the efficacy and outcome of the reaction was observed.
\end{abstract}

Keywords: phenylpropanoid glycerides, Mitsunobu esterification, deprotection.

\section{Introduction}

Phenylpropanoid glycerides are found as minor components in propolis and different Liliacea, Juncaceae, and Gramineae plant species [1-5]. Some of them possess interesting biological properties, such as antialgal [4], antitumor [6], and antiproliferative activities [2]. The presence of one or two phenolic groups attached to the cinnamoyl moiety makes phenolic glycerides very promising 
antioxidants. However, except for monoferuloyl glycerol [7], which is recently used in cosmetics as a sunscreen ingredient, none of the other phenolic glycerides has been much studied. One reason is the small amount of these esters found in nature. On the other hand, their chemical synthesis via direct esterification of glycerol suffers from several difficulties. Phenolic acids are heat-sensitive and susceptible to oxidation under certain $\mathrm{pH}$ conditions; further, they require both protection of the phenolic hydroxyl group and a mild deprotection step [8]. In, addition, acyl migration is a commonly occurring phenomenon in glyceride syntheses that can be provoked by bases, acids and high temperatures [9]. In search of suitable benign conditions lipases have been examined as an attractive alternative. However, lipases have turned out to be unfit for direct esterification of glycerol with substituted cinnamic acids or anhydrides because they are strongly inhibited by the electron-donating $p$-substituents in the cinnamic acid system [8].

Recently, some esters of caffeic acid have been prepared in one step under the mild conditions of the Mitsunobu reaction [10]. Since this method has been proven to give carboxylates rather than phenates we decided to try it out for synthesis of natural esters of glycerol and cinnamic, ferulic, $p$-coumaric and caffeic acids. In order to only obtain monoglycerides, we started from $R, S$-solketal instead of glycerol, and transformed it into phenolic acids esters by the Mitsunobu protocol, and deprotected the resulted acetonides with wet Amberlyst 15. During the syntheses some unexpected results were obtained concerning the reactivity of the acids and the yield of the products.

\section{Results and Discussion}

Following the procedure described by Appendino et al. [10], commercially available $R, S$-solketal was subjected to the Mitsunobu esterification with 1 molar equivalent of cinnamic, ferulic, $p$-coumaric and caffeic acids (Scheme 1). Reactions were complete within 48 hours. Yields are shown in Scheme 1.

Scheme 1. Synthesis of phenolic monoglycerides.
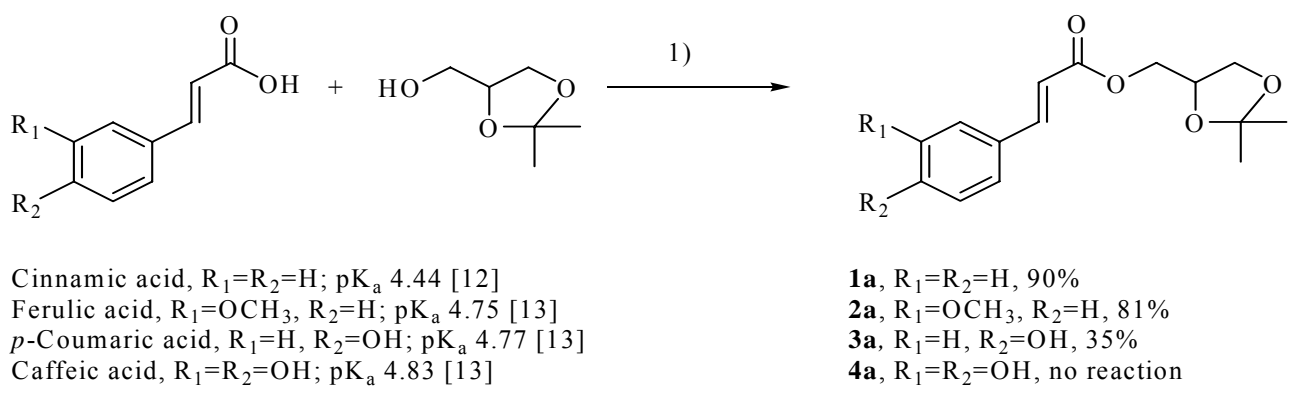

2)

1) DEAD, TPP, dry THF;

2) Amberlyst 15 (wet) in 95\% EtOH<smiles>[R3]c1ccc(/C=C/C(=O)OCC(O)CO)cc1Br</smiles> 
The reaction mixtures contained the desired products, accompanied by some unreacted starting materials, diethylhydrazine dicarboxylate byproducts and triphenylphosphine oxide. No ethers were found. The acetonides were much more polar than triphenylphosphine oxide and were easily isolated by column chromatography on silica gel. The acetonides were further deprotected after refluxing with wet Amberlyst 15 [11] in 95\% EtOH for 3 hours. Thus, the phenolic monoglycerides were obtained in over 95\% yield after simple filtration and evaporation of the solvent. All acetonides and glycerides were characterized by NMR and MS spectra. The results from the acetonide syntheses supported the recent investigations on the Mitsunobu reaction according to which the yields of the esters strongly depend on the acid strength [14-16]. As a rule a more basic carboxylate species delays the $\mathrm{S}_{\mathrm{N}} 2$ displacement, which is the final ester bond-forming step of the Mitsunobu reaction and this in lower yields of esters. The weaker phenolic acids used in this study also gave acetonides in lower yields than the stronger acids. Thus, depending on the starting phenolic acid the yield of the acetonides decreased in the following order: cinnamic 1a (90\%), ferulic 1b (81\%) and p-coumaric acids 1c (35\%) (Scheme 1). Although caffeic acid had the highest $\mathrm{pK}_{\mathrm{a}}$ value it was quite surprising that it did not react at all, whereas with the same protocol Appendino et al. [10] obtained esters of caffeic acid with phenylethanol (54\%), pentenol (42\%) and octanol (59\%). In our hands, the Mitsunobu reaction of caffeic acid and octanol also produced octyl caffeate 5 (45\%). Apparently, at these reaction conditions caffeic acid is a good coupling partner for non-sterically hindered primary alcohols and does not react efficiently with the relatively encumbered isopropylidene glycerol. Forcing the acid-alcohol stoichiometric ratio to $2: 1$ did not lead to ester formation either. This was only achieved with replacement of the caffeic acid with the stronger phenolic acids. It turned out that such a phenomenon concerning dramatic increases in product yields, when the starting material is a sterically hindered alcohol and only the acidic component is changed to a stronger one is well documented and this is not the first report concerning primary alcohols [14].

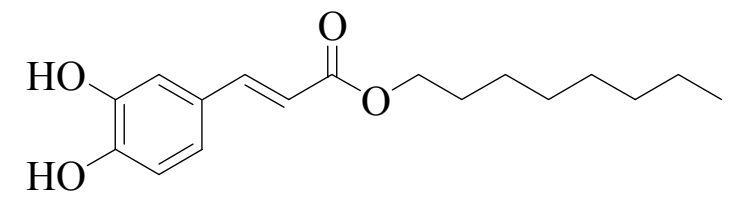

5

On the other hand, as that can be seen from the values in Scheme 1 that despite their very similar $\mathrm{pK}_{\mathrm{a}}$ values, ferulic and $p$-coumaric acid gave esters in drastically different yields. Some mechanistic studies on the Mitsunobu esterification have demonstrated that the weaker acids possess high equilibrium constants in THF and other non-polar solvents because of the strong hydrogen bonds between the acids and their carboxylates [17]. Both ferulic and p-coumaric acids possess phenolic hydroxyls in their molecules, which contribute to the possibility of the hydrogen bond formation. However, due to the lack of sterically hindered environments around their phenolic hydroxyls, the carboxylates generated from p-coumaric acid tend to easily form hydrogen bonds. Thus, theadduct formed between triphenylphosphine and diethyl azodicarboxylate is additionally destabilized in the presence of $p$-coumaric acid and that diminishes the yield of its ester. 
Up-to-now some phenolic monoglycerides have been prepared through a reaction of the chloride of the protected phenolic acid and isopropylidene glycerol and further removal of the isopropylidene group by acid hydrolysis in overall yields of around 6\%. [18]. In comparison, the Mitsunobu reaction in combination with the deprotection step with Amberlyst gave the monoglycerides of cinnamic, ferulic and $p$-coumaric acids $\mathbf{1 b}$-3b in overall yields of 89,79 , and $34 \%$, respectively.

\section{Conclusions}

The Mitsunobu esterification of isopropylidene glycerol with cinnamic, ferulic and $p$-coumaric acids followed by the deprotection of the acetonides with Amberlyst 15 resin appears to be a good method for the synthesis of the correspondent phenolic monoglycerides. It can be also useful for the preparation of the monoglycerides of other acids having hydroxyl groups, except for caffeic acid, which is highly non reactive towards isopropylidene alcohol under the conditions of the employed Mitsunobu protocol.

\section{Acknowledgements}

The scholarship from JSPS for the post-doctoral research of Dr. Batovska is greatly acknowledged. This work was partly supported by a Grant-in Aid for Scientific Research provided by the Japan Society for the Promotion of Science.

\section{Experimental}

\section{General}

${ }^{1} \mathrm{H}$ and ${ }^{13} \mathrm{C}$-NMR spectra were recorded on a JEOL EX-270 spectrometer for $\mathrm{CDCl}_{3}$ solutions (unless otherwise indicated) with TMS as internal standard. $J$ values are given in hertz (Hz). Mass spectra (EI, HRMS) were obtained with JEOL JMS AX-500. Melting points were determined on Mettler FP5 and are uncorrected. Column chromatography was performed on silica gel (Merck). Cinnamoyl, ferulic, p-coumaric, and caffeic acids, $R, S$-2,2-dimethyl-1,3-dioxolane-4-methanol, octanol, triphenylphosphine and diethyl azodicarboxylate were purchased from Wako. Amberlyst 15J (wet) was from Organo. Tetrahydrofuran (Riedel-de-Haen) was distilled from $\mathrm{LiAlH}_{4}$ prior to use. The Mitsunobu reaction was conducted in oven-dried glassware under nitrogen atmosphere.

Synthesis of the isopropylidene derivatives of the phenolic acids 1a-3a and octyl caffeate $\mathbf{5}$ via the Mitsunobu protocol

Triphenyl phosphine $(794 \mathrm{mg}, 3.03 \mathrm{mmol})$ was added to a cooled $\left(0^{\circ} \mathrm{C}\right)$ solution of acid $(3.03 \mathrm{mmol})$ and alcohol $(3.03 \mathrm{mmol})$ in dry THF $(20 \mathrm{~mL})$. Diethyl azodicarboxylate $(551 \mu \mathrm{L}, 3.03 \mathrm{mmol})$ was added in a dropwise fashion and the reaction mixture was then stirred at room temperature for $48 \mathrm{~h}$. The solvent was removed and the residue was dissolved in EtOAc and washed with saturated aq. $\mathrm{NaHCO}_{3}(3 \times 50$ 
$\mathrm{mL})$ and saturated aq. $\mathrm{NaCl}(50 \mathrm{~mL})$, dried over $\mathrm{Na}_{2} \mathrm{SO}_{4}$ and then evaporated. The products were purified by column chromatography over silica gel with $n$-hexane-EtOAc as eluent.

(2,2-Dimethyl-1,3-dioxolane-4-yl)methyl cinnamate (1a). White crystals, m.p. $44.2^{\circ} \mathrm{C} ;{ }^{1} \mathrm{H}-\mathrm{NMR}: \delta 7.71$ (d, 1H, J=15.9), 7.51-7.37 (m, 5H), 6.47 (d, 2H, J=15.9), 4.44-4.36 (m, 1H), 4.31 (dd, 1H, J=4.6, 11.3), 4.22 (dd, 1H, $J=5.9,11.6), 4.12$ (dd, $1 \mathrm{H}, J=6.5,8.4), 3.80$ (dd, $1 \mathrm{H}, J=5.9,8.1$ ), 1.46 (s, 3H), 1.39 (s, 3H); ${ }^{13} \mathrm{C}-\mathrm{NMR}: \delta 166.5,145.3,134.2,130.3,128.8,128.0,117.4,109.8,74.9,73.8,66.4,27.3,26.8$; EIMS m/z $262[\mathrm{M}]^{+}$(3.8), 247 (100.0), 204 (9.9), 148 (4.9), 131 (61.6), 114 (7.3), 103 (19.7), 101 (15.9), 77 (9.4), 73 (2.8), 43 (6.5); HREIMS m/z 262.1229 [M] (calcd for $\mathrm{C}_{15} \mathrm{H}_{18} \mathrm{O}_{4}$ 262.1205).

(2,2-Dimethyl-1,3-dioxolane-4-yl)methyl ferulate (2a). Colorless oil; ${ }^{1} \mathrm{H}-\mathrm{NMR}: \delta 7.64(\mathrm{~d}, 1 \mathrm{H}, J=16.2)$, 7.08-7.02 (m, 2H), 6.91 (d, 1H, J=8.1), 6.33 (d, 1H, J=15.9), 5.98 (bs, 1H), 4.45-4.37 (m, 1H), 4.32 (dd, $1 \mathrm{H}, J=4.6,11.6$ ), 4.19 (dd, $1 \mathrm{H}, J=6.2,11.3$ ), 4.13 (dd, $1 \mathrm{H}, J=6.5,8.4), 3.92$ (s, 3H), 3.80 (dd, $1 \mathrm{H}, J=5.7$, 8.4), 1.47 (s, 3H), 1.49 (s, 3H); ${ }^{13} \mathrm{C}-\mathrm{NMR}: \delta 166.8,147.9,146.6,145.4,126.7,123.1,114.7,114.6,109.8$, 109.2, 73.8, 66.3, 64.8, 55.9, 26.8, 25.4; EIMS m/z 308 [M] (56.3), 293 (71.4), 277 (5.2), 262 (26.1), 250 (11.0), 194 (52.1), 177 (100.0), 145 (29.7), 135 (7.3), 117 (29.1), 101 (26.6), 89 (8.1), 72 (7.5), 43 (22.0); HREIMS m/z 308.1223 [M] $]^{+}$(calcd for $\mathrm{C}_{16} \mathrm{H}_{20} \mathrm{O}_{6} 308.1260$ ).

(2,2-Dimethyl-1,3-dioxolane-4-yl)methyl p-coumarate (3a). Pale yellow crystals, m.p. $127.4^{\circ} \mathrm{C}$; ${ }^{1} \mathrm{H}-\mathrm{NMR}: \delta 7.71$ (d, 1H, J=15.9), 7.51-7.37 (m, 5H), 6.47 (d, 2H, J=15.9), 4.44-4.36 (m, 1H), 4.31 (dd, $1 \mathrm{H}, J=4.6,11.3$ ), 4.22 (dd, $1 \mathrm{H}, J=5.9,11.6), 4.12$ (dd, $1 \mathrm{H}, J=6.5,8.4), 3.80$ (dd, $1 \mathrm{H}, J=5.9,8.1$ ), 1.46 (s, $3 \mathrm{H}), 1.39(\mathrm{~s}, 3 \mathrm{H}) ;{ }^{13} \mathrm{C}-\mathrm{NMR}\left(\mathrm{CDCl}_{3}\right): \delta 166.1,157.7,145.0,129.9,128.8,127.1,115.8,114.9,109.9$, 73.9, 66.4, 64.8, 26.8, 25.5; EIMS m/z 278 [M] (16.8), 263 (44.9), 220 (6.8), 178 (1.4), 165 (3.9), 164 (34.3), 147 (100.0), 119 (19.1), 101 (28.5), 91 (25.9), 72 (10.6), 65 (10.9), 43 (14.5); HREIMS m/z $278.1168[\mathrm{M}]^{+}$(calcd for $\mathrm{C}_{15} \mathrm{H}_{18} \mathrm{O}_{5} 278.1154$ ).

Octyl caffeate (5). White solid; ${ }^{1} \mathrm{H}-\mathrm{NMR}$ : $\delta 7.56$ (d, $\left.1 \mathrm{H}, J=16.2\right), 7.07$ (s, 1H), 6.99 (d, 1H, J=8.1), 6.85 $(\mathrm{d}, 1 \mathrm{H}, J=8.1), 6.25$ (d, 1H, J=15.7), 4.18 (t, 2H, $J=6.5), 1.60-1.55$ (m, 2H), $1.28(\mathrm{~s}, 8 \mathrm{H}), 0.88(\mathrm{t}, 3 \mathrm{H}$, $J=6.6) ;{ }^{13} \mathrm{C}-\mathrm{NMR}\left(\mathrm{CDCl}_{3}\right): \delta 167.3,149.5,140.1,133.7,128.6,126.9,122.7,121.1,114.1,63.2,32.9$, 31.9, 29.3, 29.2, 25.8, 22.7, 14.2; EIMS m/z 293 [M+1] (7.3), 292 (37.4), 278 (18.9), 277 (29.6), 262 (17.4), 199 (6.6), 180 (100.0), 163 (38.5), 149 (7.1), 136 (13.1), 135 (12.0), 134 (10.4), 89 (7.2), 77 (8.8), 69 (10.3), 55 (12.5), 44 (59.6), 40 (53.8); HREIMS m/z 292.1683 [M] (calcd for $\mathrm{C}_{17} \mathrm{H}_{24} \mathrm{O}_{4} 292.1675$ ).

Deprotection of the isopropylidene derivatives to the monoglycerides $\mathbf{1 b}-\mathbf{b} \mathbf{b}$ [11].

A solution of acetonide $(50 \mathrm{mg})$ in $95 \%$ ethanol $(5 \mathrm{~mL})$ was refluxed for $4 \mathrm{~h}$ in the presence of Amberlyst 15 (wet) ion-exchange resin $(8 \mathrm{mg}$ ). The reaction mixture was filtered and the filtrate was concentrated to give the corresponding monoglycerides. 
1-O-Cinnamoyl glycerol (1b). Colorless oil; ${ }^{1} \mathrm{H}-\mathrm{NMR}$ : $\delta 7.71(\mathrm{~d}, 1 \mathrm{H}, J=16.2), 7.54-7.51(\mathrm{~m}, 2 \mathrm{H})$, 7.41-7.38 (m, 3H), 6.47 (d, 1H, J=15.9), 4.35 (dd, 1H, $J=4.3,11.6), 4.29$ (dd, 1H, $J=5.7,11.3), 4.07-4.00$ (m, 1H), $3.75(\mathrm{dd}, 1 \mathrm{H}, J=3.5,11.6), 3.66(\mathrm{dd}, 1 \mathrm{H}, J=5.7,11.3), 2.80(\mathrm{bs}, 1 \mathrm{H}), 2.36(\mathrm{bs}, 1 \mathrm{H}) ;{ }^{13} \mathrm{C}-\mathrm{NMR}$ $\left(\mathrm{CDCl}_{3}\right): \delta 167.2,145.8,133.9,130.5,128.8,128.1,117.1,70.3,65.4,63.3 ;$ EIMS m/z $222[\mathrm{M}]^{+}(2.9)$, 204 (2.3), 191 (13.1), 149 (18.1), 131 (100.0), 103 (27.2), 83 (7.9), 77 (11.9), 69 (3.2), 43 (3.5), 41 (0.9); HREIMS m/z 222.0881 [M] ${ }^{+}$(calcd for $\mathrm{C}_{12} \mathrm{H}_{14} \mathrm{O}_{4} 222.0892$ ).

1-O-Feruloyl glycerol (2b). Colorless oil; ${ }^{1} \mathrm{H}-\mathrm{NMR}$ : $\delta 7.65$ (d, 1H, J=15.7), 7.09-6.91 (m, 3H), 6.31 (d, $1 \mathrm{H}, J=15.7), 5.93$ (s, 1H), 4.39 (dd, $1 \mathrm{H}, J=4.6,12.2), 4.28-4.19$ (m, 1H), 4.12 (dd, $1 \mathrm{H}, J=6.5,8.4), 3.93$ (s, 3H), 3.80 (dd, $1 \mathrm{H}, J=6.2,8.4), 3.70$ (dd, $1 \mathrm{H}, J=5.7,12.3), 2.69$ (bs, $1 \mathrm{H}) .2 .23$ (bs, $1 \mathrm{H}) ;{ }^{13} \mathrm{C}-\mathrm{NMR}$ $\left(\mathrm{CDCl}_{3}\right): \delta 167.5,148.1,146.7,145.9,126.6,123.2,120.4,114.7,114.4,70.4,65.3,63.4,55.9$; EIMS

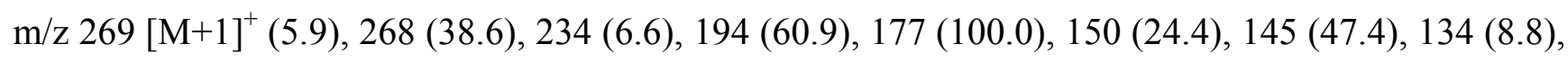
117 (18.2), 89 (14.5), 77 (8.7), 51 (6.1), 44 (16.3), 40 (12.9); HREIMS m/z 268.0957 [M] ${ }^{+}$(calcd for $\left.\mathrm{C}_{13} \mathrm{H}_{16} \mathrm{O}_{6} 268.0947\right)$.

1-O-p-Coumaroyl glycerol (3b). Yellow crystals, m.p. $109.3{ }^{\circ} \mathrm{C} ;{ }^{1} \mathrm{H}-\mathrm{NMR}\left(\mathrm{CD}_{3} \mathrm{OD}\right): \delta 7.65(\mathrm{~d}, 1 \mathrm{H}$, $J=15.9$ ), 7.46 (d, 2H, $J=8.4$ ), 6.80 (d, 2H, $J=8.6$ ), 6.35 (d, 1H, $J=15.9), 4.26$ (dd, 1H, $J=4.3,11.3$ ), 4.16 (dd, $1 \mathrm{H}, J=6.2,11.3), 3.88(\mathrm{t}, 1 \mathrm{H}, J=5.1), 3.75$ (d, 2H, $J=5.4), 3.66(\mathrm{dd}, 1 \mathrm{H}, J=5.7,11.3) ;{ }^{13} \mathrm{C}-\mathrm{NMR}$ $\left(\mathrm{CD}_{3} \mathrm{OD}\right): \delta 168.9,156.2,146.6,131.0,130.5,128.1,116.7,114.9,71.3,66.5,64.1 ; \mathrm{EIMS} \mathrm{m} / \mathrm{z} 238[\mathrm{M}]^{+}$ (13.5), 207 (6.5), 178 (1.0), 165 (9.2), 164 (34.6), 147 (100.0), 119 (20.2), 91 (14.9), 89 (3.4), 65 (7.5), 45 (5.9), 43 (5.0); HREIMS m/z $238.0845[\mathrm{M}]^{+}$(calcd for $\mathrm{C}_{12} \mathrm{H}_{14} \mathrm{O}_{5} 238.0841$ ).

\section{References}

1. Bankova, V.; Popova, M.; Bogdanov, St.; Sabatini, A.-G. Chemical composition of European propolis: expected and unexpected results. Z. Naturforsch. 2002, 57c, 530-533.

2. Banskota, A.H.; Nagaoka, T.; Sumioka L.Y.; Tezuka, Y.; Awale, S.; Midorikawa, K.; Matsushige, K.; Kadota, S. Antiproliferative activity of the Netherlands propolis and its active principles in ccancer cell lines. J. Etnopharmacol. 2000, 80, 67-73.

3. Shimomura, H.; Sashida, Y.; Mimaki, Y. Phenolic glycerides from Lilium auratum. Phytochemistry 1987, 26, 844-845.

4. Dellagreca, M.; Fiorentino, A.; Monaco, P.; Previtera, L.; Sorrentino, M. Antialgal phenylpropane glycerides from Juncus effusus. Nat. Prod. Lett. 1998, 12, 263-270.

5. Fenz, R.; Ludger, E.; Galensa, R. Phenolic acids and their glycerides in maize grits. Z. Lebensmitt.-Untersuch. Forsch. 1992, 194, 252-8.

6. Gunasekera, S.P.; Kinghorn, A.D.; Cordell, G.A.; Farnsworth, N. R. Plant anticancer agents. XIX Constituents of Aquilaria malaccensis. J. Nat. Prod. 1981, 44, 569-72.

7. Laszlo, J.A.; Compton, D.L.; Eller, F.J.; Taylor, S.L.; Isbell, T.A. Packed-bed bioreactor synthesis of feruloylated monoacyl- and diacylglycerols: clean production of a 'green' sunscreen. Green Chem. 2003, 5, 382-386. 
8. Armesto, N.; Ferrero, M.; Fernandez, S.; Gotor, V. Novel enzymatic synthesis of 4-O-cinnamoyl quinic and shikimic acid derivatives. J. Org. Chem. 2003, 68, 5784-5787.

9. Fureby, A. M.; Adlercreutz, P.; Mattiasson, B. Ann. N. Y. Acad. Sci. 1996, 799, 231-237.

10. Appendino, G.; Minassi, A.; Daddario, N.; Bianchi, F.; Tron, G. C. Chemoselective esterification of phenolic acids and alcohols. Org. Lett. 2002, 4, 3839-3841.

11. Yu, C.C.; Lee, Y.-S.; Cheon, B.S.; Lee, S.H. Synthesis of glycerol monostearate with high purity. Bull. Kor. Chem. Soc. 2003, 24, 1229-1231.

12. http://www.csudh.edu/oliver/chemdata/data-ka.htm

13. Beltran, J.L.; Sanli, N.; Fonrodona, G.; Barron, D.; Özkan, G.; Barbosa, J. Spectrophotometric, potentiometric and chromatographic $\mathrm{pK}_{\mathrm{a}}$ values of polyphenolic acids in water and acetonitrile-water media. Anal. Chim. Acta 2003, 484, 253-264.

14. Dodge, J.A.; Trujillo, J.I.; Presnell, M. Effect of the acidic component on the Mitsunobu inversion of a sterically hindered alcohol. J. Org. Chem. 1994, 59, 234-236.

15. Hughes, D.L.; Reamer, R A. The effect of acid strength on the Mitsunobu esterification reaction: carboxyl vs hydroxyl reactivity. J. Org. Chem. 1996, 61, 2967-2971.

16. Camp, D.; Jenkins, I.D. Mechanism of the Mitsunobu esterification reaction. 1. The involvement of phosphoranes and oxyphosphonium salts. J. Org. Chem. 1989, 54, 3045-3049.

17. Hughes, D.L.; Reamer, R.A.; Bergan, J.J.; Grabowski, E.J.J. A mechanistic study of the Misunobu esterification reaction. J. Am. Chem. Soc. 1988, 110, 6487-6491.

18. Thewlis, B.H. New synthetic antioxidants based on caffeic acid. J. Food Technol. 1967, 2, 83-7.

Sample availability: Contact the authors.

(C) 2005 by MDPI (http://www.mdpi.org). Reproduction is permitted for noncommercial purposes. 